(C) The Authors 2018. This is an Open Access article, distributed under the terms of the Creative Commons Attribution licence (http:// creativecommons.org/licenses/by/4.0/), which permits unrestricted reuse, distribution, and reproduction in any medium, provided the original work is properly cited.

\title{
Prevalence and determinants of vitamin D deficiency in the third trimester of pregnancy: a multicentre study in Switzerland
}

\author{
Jean-Philippe Krieger ${ }^{1 *}$, Sophie Cabaset ${ }^{1}$, Claudia Canonica ${ }^{2}$, Ladina Christoffel $^{3}$, Aline Richard ${ }^{1}$, \\ Therese Schröder $^{3}$, Begoña Lipp von Wattenwyl ${ }^{2}$, Sabine Rohrmann ${ }^{1}$ and Katharina Quack Lötscher ${ }^{4}$ \\ ${ }^{1}$ Division of Chronic Disease Epidemiology, Epidemiology, Biostatistics and Prevention Institute, University of Zurich, \\ Hirschengraben 82, 8001 Zurich, Switzerland \\ ${ }^{2}$ Gynecology and Obstetrics, Regional Hospital of Bellinzona, Carrale Morinascio 7A, 6500 Bellinzona, Switzerland \\ ${ }^{3}$ Gynecology Unit, Oberengadin Hospital, Via Nuova 3, 7503 Samedan, Switzerland \\ ${ }^{4}$ Clinic of Obstetrics, University Hospital Zurich, Frauenklinikstrasse 10, 8006 Zurich, Switzerland
}

(Submitted 24 July 2017 - Final revision received 8 November 2017 - Accepted 5 December 2017-First published online 10 January 2018)

\section{Abstract}

Vitamin D deficiency during pregnancy is associated with negative health consequences for mothers and their infants. Data on the vitamin D status of pregnant women in Switzerland are scarce. A three-centre study was conducted in the obstetric departments of Zurich, Bellinzona and Samedan (Switzerland) to investigate the prevalence and determinants of vitamin D deficiency (serum 25-hydroxyvitamin D (25(OH)D) $<50 \mathrm{nmol} / \mathrm{l}$ ) in 3rd-trimester pregnant women living in Switzerland ( $n$ 305), and the correlation between 25(OH)D in pregnant women and their offspring at birth ( $n$ 278). Demographic and questionnaire data were used to explore the determinants of vitamin D deficiency. Median concentration of serum $25(\mathrm{OH}) \mathrm{D}$ in the third trimester of pregnancy was $46 \cdot 0 \mathrm{nmol} / 1$ (1st-3rd quartiles: $30 \cdot 5-68 \cdot 5)$, representing a $53 \cdot 4 \%$ prevalence of vitamin D deficiency. 25(OH)D levels in the umbilcal cord blood (median: $50 \cdot 0 \mathrm{nmol} / 1$; 1 st-3rd quartiles: $31 \cdot 0-76 \cdot 6)$ strongly correlated with mothers' serum 25(OH)D (Spearman's correlation $\rho=0.79, P<0 \cdot 001)$. Multivariable logistic regression analysis showed that significant determinants of vitamin D deficiency in pregnant women were centre of study, country of origin, season of delivery and vitamin D supplement intake. Near-term BMI, skin colour, use of sunscreen and mothers' education, although each not individually significant, collectively improved the ability of the model to explain vitamin D status. Low vitamin D levels were common in this sample of pregnant women and their newborns' cord blood. Vitamin D supplement intake was the most actionable determinant of vitamin D status, suggesting that vitamin D supplementation during pregnancy should receive more attention in clinical practice.

\section{Key words: 25-Hydroxy-vitamin D: Hypovitaminosis: Cord blood: Vitamin supplementation: Neonates}

Vitamin D deficiency has been demonstrated in various populations and is therefore considered a widespread health issue $^{(1,2)}$. The discovery that vitamin $\mathrm{D}$ is required for normal human growth and development has brought increasing attention to the potential health consequences of vitamin D deficiency during pregnancy ${ }^{(3)}$.

Numerous studies have investigated the risks in mothers associated with low vitamin D levels during pregnancy ${ }^{(4)}$. In summary, there is evidence to suggest a link between low vitamin D status during pregnancy and preeclampsia, gestational diabetes and preterm delivery ${ }^{(4-6)}$. Moreover, 25-hydroxyvitamin D (25 $(\mathrm{OH}) \mathrm{D})$ concentrations in cord blood strongly correlate with maternal concentrations ${ }^{(7-10)}$ : thus, vitamin D deficiency in pregnant women may also negatively impact fetal development. Some evidence indicates that babies' body size, bone mineralisation or risk of acute lower respiratory infections may be affected by low vitamin D status during pregnancy ${ }^{(3,4)}$.
While these associations require further confirmation, they raise the question of vitamin D sufficiency in pregnant women. Studies reporting the prevalence of vitamin D deficiency in pregnant women are not easily comparable because cut-off values for vitamin $\mathrm{D}$ deficiency and insufficiency in pregnant women were not uniformly defined ${ }^{(11-14)}$. Nevertheless, in all populations studied, the reported prevalence of vitamin D deficiency was consistently high at or near term ${ }^{(15,16)}$. These data, however, are not available for women in late pregnancy living in Switzerland. In addition, there are currently no data assessing the vitamin D status of neonates in Switzerland, and no $25(\mathrm{OH}) \mathrm{D}$ cut-off values are currently defined for newborns.

Reported determinants of vitamin D status in pregnant women are partly identical to those of the general population, including skin pigmentation, adiposity status, latitude of residence, dietary intake, use of vitamin supplements, wearing of skin-covering clothes or sunscreen $u^{(7,12,17-19)}$. These

Abbreviation: 25(OH)D, 25-hydroxyvitamin D.

* Corresponding author: J.-P. Krieger, email jean-philippe.krieger2@uzh.ch 
determinants, however, appear to be country and culturally specific $^{(1,15)}$. For example, classic determinants of vitamin D status fail to fully explain the high prevalence of vitamin D inadequacy in pregnant women of the Mediterranean region ${ }^{(20)}$. Interestingly, Switzerland is characterised by several factors that are indirectly linked with known vitamin D determinants: a unique blend of cultural influences, a large foreign population, a high diversity of meteorological conditions (e.g. Alpine and Mediterranean) and a large variability of altitude of residence. Consequently, there are reasons to believe that the determinants of vitamin D status in Swiss pregnant women may differ from other populations.

Moreover, in studies looking at vitamin D deficiency, many determinants are often reported, such as latitude of residence, season or physical activity ${ }^{(21,22)}$. This raises the question whether they are all equally important and whether there may be redundant factors. The comparative analysis of several regression models could help strengthen the identification of determinants $^{(23)}$ and potentially lead to simple prediction models of great use in routine clinical practice ${ }^{(24)}$

In this study, we measured serum $25(\mathrm{OH}) \mathrm{D}$ levels in women living in Switzerland during the third trimester of pregnancy and in the cord blood of their offspring at birth. To better capture the potential heterogeneity of the Swiss population, we conducted the study in three centres representing regions of different cultural and meteorological influences. These data, together with demographic and questionnaire data, allowed us to: (1) determine the prevalence of vitamin D deficiency in pregnant women and their neonates, (2) identify the significant determinants of vitamin D deficiency in pregnant women and (3) test the relative importance of the selected determinants of vitamin D deficiency using a comparative analysis of several logistic regression models. Altogether, our data contribute to increased knowledge regarding maternal and neonatal vitamin deficiency in the Swiss population.

\section{Methods}

\section{Study population}

The multicentre study was conducted between August 2014 and June 2016 at the obstetrics departments of the Zurich University Hospital, the Regional Hospital of Bellinzona and the Hospital of Oberengadin in Samedan. Women were conveniently recruited in the three centres during their last routine examination - that is within days before delivery (pregnancy weeks 36-42). Twin pregnancy, HIV, history of parathyroid, renal or liver disease, chronic malabsorption syndromes or granulomaforming disorders, age below 18 years and known or suspected drug or alcohol abuse were used as exclusion criteria.

The study was not designed to be representative of the whole Swiss population, but the choice of the three centres takes into account the cultural, socio-demographic and meteorological heterogeneity of Switzerland. Centre regional characteristics are recapitulated in Fig. 1. In brief, Zurich is a densely populated urban area with mild climate. The Bellinzona region is a less densely populated area, with high temperatures and sunshine time, and belongs to the Italian-speaking region of Switzerland. The Samedan centre is located in a rural region characterised by high altitude and low annual average temperatures. Meteorological data were supplied by IDAWEB (Swiss Federal Office of Meteorology and Climatology MeteoSwiss): monthly total

(a)

(b)

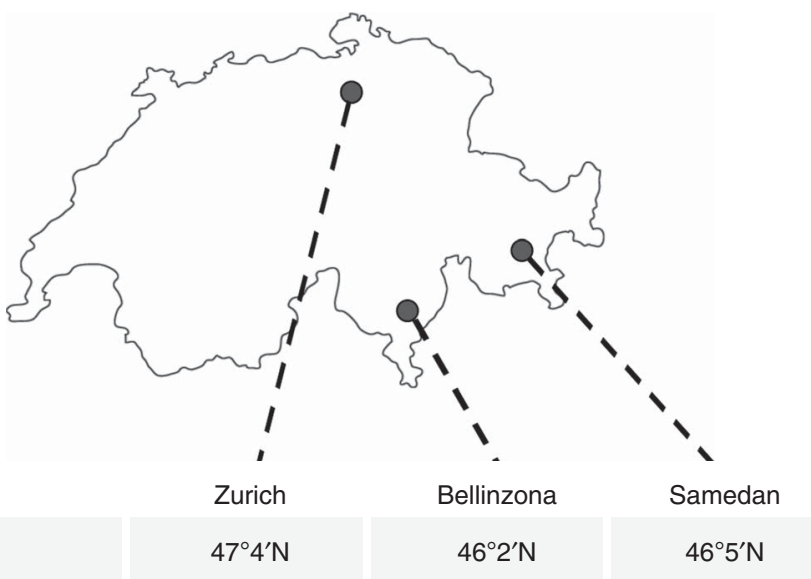

\begin{tabular}{|c|c|c|c|}
\hline Latitude & $47^{\circ} 4^{\prime} \mathrm{N}$ & $46^{\circ} 2^{\prime} \mathrm{N}$ & $46^{\circ} 5^{\prime} \mathrm{N}$ \\
\hline Altitude (m) & 408 & 238 & 1721 \\
\hline $\begin{array}{l}\text { Total sunshine duration } \\
\text { (h during study period) }\end{array}$ & 3090 & $4080^{(1)}$ & 3293 \\
\hline $\begin{array}{l}\text { Mean air temperature } \\
\left({ }^{\circ} \mathrm{C} \text { during study period) }\right.\end{array}$ & $10 \cdot 1$ & $13 \cdot 1$ & $2 \cdot 9$ \\
\hline $\begin{array}{l}\text { Population density in the canton } \\
\text { (inhabitants } / \mathrm{km}^{2} \text { in 2016) }\end{array}$ & 895.9 & $129 \cdot 3$ & $27 \cdot 8$ \\
\hline
\end{tabular}

Fig. 1. (a) Geographical distribution, (b) meteorological characteristics of the three study centres (source MeteoSwiss ${ }^{(1)}$, indicates that data were not available for Bellinzona and replaced by the neighbouring weather station of Locarno-Monti) and population density of the respective cantons (source Federal Statistical Office, Statistical Atlas of Switzerland $\left.{ }^{(25)}\right)$. 
sunshine duration in hours and monthly mean of air temperature $2 \mathrm{~m}$ above the ground were, respectively, summed and averaged over the study period (August 2014 to June 2016). Meteorological data were not available for Bellinzona and replaced by the neighbouring weather station of Locarno-Monti (20 km away). Demographic data are based on the Federal Statistical Office Swiss Atlas Data ${ }^{(25)}$ and reflect the cantonal mean.

\section{Justification of sample size}

A true sample size calculation for our main analyses, the multivariable logistic regressions, required information that was unavailable in practice, such as the coefficients of determination between covariates. We therefore followed the indication of Agresti $^{(26)}$ to include a minimum of ten participants per covariate (305 participants for a maximum of fifteen covariates in model 1).

\section{Ethical approval}

This study was conducted according to the guidelines set forth in the Declaration of Helsinki, and all procedures involving human subjects were approved by the Zurich cantonal ethics committee (KEK-ZH-0213). Written informed consent was obtained from all subjects.

\section{Blood collection}

A 10-ml blood sample was taken from pregnant women during the last routine examination before delivery. Umbilical cord blood was taken postpartum from the umbilical vein after clamping.

\section{Measurements of serum 25-hydroxyvitamin D}

Vitamin D status was evaluated by measuring the concentration of serum $25(\mathrm{OH}) \mathrm{D}$, the main circulating metabolite of vitamin $\mathrm{D}$, thus reflecting both dietary intake and endogenous production. Blood samples from mothers and umbilical cord were analysed locally: the Institute of Clinical Chemistry of the Zurich University Hospital and Viollier AG for the Samedan Hospital used a vitamin D total-analysis Roche Cobas electrochemiluminescence immunoassay (Roche Diagnostics). The method has a detection range of $7 \cdot 5-175 \mathrm{nmol} / \mathrm{l}$ for $25(\mathrm{OH}) \mathrm{D}$ and a variation coefficient of $2 \cdot 2-6 \cdot 8 \%$. The Department of Laboratory Medicine of Bellinzona Cantonal Hospital used an Agilent LC-MS/ MS 6490 equipped with an 1290 LC series with the Chromsystems IVD kits and an automatic sample preparation (MassStar). The interassay variation coefficient was $6.5-9.3 \%$.

\section{Definition of vitamin D deficiency}

We chose a cut-off value of $50 \mathrm{nmol} / 1$, as proposed by several authorities, including the Endocrine Society ${ }^{(27)}$, the International Osteoporosis Foundation ${ }^{(28)}$ or the Canadian Osteoporosis Society ${ }^{(29)}$. Therefore, vitamin D deficiency was defined as serum level $<50 \mathrm{nmol} / 1$ and sufficiency as $\geq 50 \mathrm{nmol} / \mathrm{l}$. Because no 25(OH)D cut-off values are currently defined for neonates (or cord blood), neonates were not referred to as sufficient or deficient.

\section{Potential determinants of vitamin D status in pregnant women}

On the basis of a questionnaire and data collected by physicians, the following variables were used as potential determinants: study centre (Zurich $v$. Bellinzona $v$. Samedan), age, week of pregnancy, nulliparity (yes $v$. no), first pregnancy (yes $v$. no), self-reported BMI before pregnancy, measured BMI at near term, body weight gained during pregnancy, skin colour (light $v$. dark), country of origin (in five groups), education level achieved by the mother, education level achieved by the partner (less than compulsory education $v$. compulsory education $v$. secondary education $v$. tertiary education), smoking status (never $v$. former $v$. current), season (winter (21 December-20 March) $v$. spring (21 March-20 June 20th) $v$. summer (21 June20 September) $v$. autumn (21 September-20 December)), average number of days per week spent at least $1 \mathrm{~h}$ outdoor between 10.00 and 16.00 hours in the past 6 months, frequency of sunscreen use when exposed to the sun in the summer (never $v$. sometimes $v$. always), consumption of fish (herring, salmon, mackerel, sardine or tuna) at least once a week (yes $v$. no) and intake of vitamin D-containing supplements (yes $v$. no).

The countries of origin were grouped into five categories based on the local population and the regions defined by the World Bank, as previously reported ${ }^{(19)}$ : (1) Switzerland and Germany; (2) Northern America, Northern Europe, Central Asia and New Zealand; (3) Southern Europe, Australia and Latin America; (4) South and East Asia and Pacific; and (5) Africa and Middle East.

To assess skin colour, we used a five-level scale ${ }^{(19)}$ adapted from Fitzpatrick's classification method ${ }^{(30)}$. Briefly, the participants evaluated their phototype by choosing among five pictures the one that best represents their skin colour and describing how their untanned skin reacts to sun exposure (if exposed in the early summer at noon for 45-60 min). Physicians also evaluated the participants' skin colour. When the classification of the participant and the physician disagreed, the rounded arithmetic mean was taken. To account for the small amount of women in groups IV and V, the skin colour variable was then dichotomised into light skin colour (Fitzpatrick levels I to III) and dark skin colour (Fitzpatrick levels IV and V).

\section{Descriptive analyses}

All analyses and graphs were conducted using R (version 3.3.2 for Mac). Boxplots represent the medians and 1 st and 3rd quartiles of the complete cases. Prevalence of vitamin D deficiency between centres was compared using KruskalWallis test followed by pairwise comparisons using Tukey's and Kramer-Nemenyi test with Tukey-Dist approximation for independent samples. The correlation between serum 25(OH)D levels of pregnant women and the cord blood of their neonates was determined using Spearman's correlation coefficient $\rho$. $P$ values $\leq 0.05$ were considered significant.

\section{Logistic regression analyses of the determinants of vitamin D deficiency}

To increase the number of cases available for logistic regression, we assumed that data were missing at random and performed multiple imputation with chained equations $(m=25$, 
mice package version 2.30 for $\left.\mathrm{R}^{(31)}\right)$. We estimated univariable associations of $25(\mathrm{OH}) \mathrm{D}$ deficiency with potential determinants using logistic regressions, with the following variables: study centre, age, week of pregnancy, nulliparity, first pregnancy, BMI before pregnancy, BMI near term, body weight gained during pregnancy, skin colour, country of origin, education level achieved by the mother, education level achieved by the partner, smoking status, season, days spent in the sun, use of sunscreen, fish consumption and intake of vitamin D-containing supplements. In addition, we performed multivariable logistic regressions using all potential determinants except variables showing high collinearity (model 1). Collinearity was defined as a Pearson's correlation coefficient above 10.61 between continuous variables and a Cramér's $V$ above 0.6 between categorical variables. Correlation coefficients and Cramér's $V$ were calculated on complete cases.

Two supplementary logistic regression models (models 2 and 3) were determined using the following criteria: model 2 included the significant determinants of model 1, as well as the variables significantly associated with vitamin D deficiency in an univariable model, whereas model 3 included only the significant determinants of model 1. For all models, the measure of association was the OR and $95 \%$ CI. Reported regression coefficients are those obtained after combination with Rubin's rules ${ }^{(27)}$.

\section{Comparative analysis of three logistic regression models of vitamin D deficiency}

For the three regression models, the Akaike information criterion (AIC) and the AUC of the receiver operating characteristics (c-statistic) were calculated on complete cases common to all models ( $n$ 219). In addition, observed $v$. predicted probability of vitamin D deficiency were plotted after recursive discretisation of the data between upper and lower halves and averaging of both the observed and predicted probabilities within each bin. Circle area is proportional to the number of observations within a bin.

\section{Results}

\section{General characteristics of the studied population}

A total of 305 women were included in the study (Table 1): $66.6 \%$ of the women were studied in Zurich ( $n$ 203), whereas the remainder was split between Bellinzona and Samedan ( $16.7 \%, n 51$ in both centres). Overall, women were on average 32.9 (SD 5.2 ) years old and $35.7 \%$ of them originated from Switzerland or Germany. Median week of pregnancy was 38 weeks, a time during which women had gained an average of 13.6 ( $\mathrm{sD} 5.7$ ) $\mathrm{kg}$ of body weight. A large majority of the women had secondary or tertiary education (69.8\%), did not smoke during pregnancy $(90 \cdot 5 \%)$, ate fish at least once a week (60.3\%) and consumed vitamin D supplements (70.8\%). Among the participants, $86.9 \%$ were fair-skinned, regularly spent time in the sun (median of $5 \mathrm{~d}$ /week during which at least $1 \mathrm{~h}$ was spent in the sun) and used sunscreen in the summer (82.3\% at least sometimes).

\section{Prevalence of vitamin D deficiency in pregnant women}

Overall, prevalence of vitamin D deficiency was $53.4 \%$ in the study sample. Median serum 25(OH)D concentration was
$46 \cdot 0 \mathrm{nmol} / 1$ (1st-3rd quartiles: 30.5-68.5) and was significantly higher in Bellinzona than in Zurich $(P<0.005)$ and Samedan $(P<0.0005)$.

\section{5-Hydroxyvitamin D levels in the umbilical cord blood of neonates}

In the cord blood of the neonates ( $n$ 283), median serum 25 $(\mathrm{OH}) \mathrm{D}$ level was $50.0 \mathrm{nmol} / 1$ (1st-3rd quartiles: $31 \cdot 0-76 \cdot 6)$, resulting in $49.8 \%$ of the neonates having a $25(\mathrm{OH}) \mathrm{D}$ concentration below $50 \mathrm{nmol} / \mathrm{l}$. A strong correlation was observed between serum 25(OH)D levels of the mothers and their neonates (Spearman's correlation $\rho=0 \cdot 79, P<0 \cdot 0001$, Fig. 2(e)).

\section{Determinants of vitamin D deficiency in pregnant women}

Univariable logistic regression showed that significant determinants of vitamin D deficiency were centre of study, near-term BMI, country of origin, education of the mother and her partner, season and use of sunscreen (Table 2). We further examined potential determinants of vitamin $\mathrm{D}$ deficiency in a multivariable logistic regression. On the basis of a correlation analysis, the following pairs of variables were considered to be collinear: nulliparity/first pregnancy (Cramér's $V=0 \cdot 85$ ), education of the mother/education of the partner (Cramér's $V=0.61$ ) and BMI before pregnancy/near-term BMI (Pearson's correlation $=0.90)$; hence, nulliparity, education of the partner and BMI before pregnancy were left out of the first multivariable model (model 1). Centre of study, country of origin and season remained significant determinants of vitamin D deficiency in this model (Table 2). In addition, the use of vitamin D supplements became strongly associated with a lower risk of vitamin D deficiency. Conversely, near-term BMI, education of the mother and use of sunscreen failed to reach statistical significance (Table 2). Surprisingly, after multivariable adjustment, a dark skin colour was moderately associated with a decreased risk of vitamin D deficiency (Table 2). The 25(OH)D values across levels of the significant determinants are shown in Fig. 2 (a-d). We used centre, near-term BMI, skin colour, country of origin, season, education of the mother, use of sunscreen and use of vitamin D supplements in a second model (model 2), and centre, country of origin, season and use of vitamin D supplements in a third model (model 3). In both cases, the odds ratios were only marginally different from those of the full multivariable model 1 (Table 2).

\section{Comparative analysis of three logistic regression models of vitamin D deficiency in pregnant women}

The AIC of models 2 and 3 were markedly smaller than the AIC of model 1 , indicating that these 2 models are more parsimonious (Fig. 3(b)). The comparison of the c-statistics indicated that model 2 has a superior ability to explain vitamin D deficiency than model 3 , and that this ability to explain is comparable to the full model 1 (Fig. 3(c) and (d)). In addition, the plots of observed $v$. expected probability indicated a satisfactory calibration of all models, with model 2 most resembling the full model 1 . Together, these model diagnostics indicate that the fit of a logistic regression model containing the four significant 
Table 1. General characteristics of the studied sample*

(Numbers and percentages; medians and first to third quartiles (Q1-Q3); mean values and standard deviations)

\begin{tabular}{|c|c|c|c|c|c|c|c|c|c|c|c|c|}
\hline & \multicolumn{3}{|c|}{ Overall } & \multicolumn{3}{|c|}{ Zurich } & \multicolumn{3}{|c|}{ Bellinzona } & \multicolumn{3}{|c|}{ Samedan } \\
\hline & $n$ & $\%$ & Missing & $n$ & $\%$ & Missing & $n$ & $\%$ & Missing & $n$ & $\%$ & Missing \\
\hline Total women included & 305 & 100 & 0 & 203 & $66 \cdot 6$ & 0 & 51 & $16 \cdot 7$ & 0 & 51 & $16 \cdot 7$ & 0 \\
\hline Mothers, $25(\mathrm{OH}) \mathrm{D}<50 \mathrm{nmol} / \mathrm{l}$ & 163 & 53.4 & 0 & 111 & 54.7 & 0 & 17 & $33 \cdot 3$ & 0 & 35 & 68.6 & 0 \\
\hline Mothers, $25(\mathrm{OH}) \mathrm{D} \mathrm{nmol} / \mathrm{l}$ & & & 0 & & & 0 & & & 0 & & & 0 \\
\hline $\begin{array}{l}\text { Median } \\
\text { Q1-Q3 }\end{array}$ & \multicolumn{2}{|c|}{$\begin{array}{c}46 \cdot 0 \\
30 \cdot 5-60 \cdot 8\end{array}$} & & \multirow{2}{*}{\multicolumn{2}{|c|}{$\begin{array}{c}44 \cdot 8 \\
29.9-69 \cdot 4 \\
83 \quad 40.9\end{array}$}} & & \multicolumn{2}{|c|}{$\begin{array}{c}63 \cdot 8 \\
41 \cdot 3-90 \cdot 4\end{array}$} & & \multicolumn{2}{|c|}{$\begin{array}{c}41 \cdot 0 \\
28 \cdot 0-52.5\end{array}$} & \\
\hline Babies, $25(\mathrm{OH}) \mathrm{D} 50 \mathrm{nmol} / \mathrm{l}$ & 141 & 49.8 & 22 & & & 17 & & & 5 & 29 & 56.9 & 0 \\
\hline Babies, $25(\mathrm{OH}) \mathrm{D}(\mathrm{nmol} / \mathrm{l})$ & \multirow{2}{*}{\multicolumn{2}{|c|}{$50 \cdot 0$}} & 22 & \multirow{2}{*}{\multicolumn{2}{|c|}{59.4}} & 17 & \multirow{2}{*}{\multicolumn{2}{|c|}{40.4}} & 5 & \multirow{2}{*}{\multicolumn{2}{|c|}{46.0}} & 0 \\
\hline Median & & & & & & & & & & & 0 & \\
\hline Q1-Q3 & \multicolumn{2}{|c|}{$31 \cdot 0-76 \cdot 6$} & & 32 . & -82.9 & & 23. & -55.4 & & & $-62 \cdot 0$ & \\
\hline Age (years) & & & 0 & & & 0 & & & 0 & & & 0 \\
\hline Mean & & & & & 3.6 & & & .2 & & & $\begin{array}{l}2 \\
6\end{array}$ & \\
\hline Week of pregnancy & & & 1 & & & 0 & & & 0 & & & 1 \\
\hline $\begin{array}{l}\text { Median } \\
\text { Q1-Q3 }\end{array}$ & & & & & $\begin{array}{l}8 \\
-38\end{array}$ & & & & & & $\begin{array}{l}9 \\
-40\end{array}$ & \\
\hline Nulliparity & 120 & 39.3 & 1 & 60 & 29.6 & 0 & 23 & $45 \cdot 1$ & 1 & 37 & $\begin{array}{l}-40 \\
72.6\end{array}$ & 0 \\
\hline First pregnancy & 102 & 33.4 & 1 & 51 & 25.1 & 0 & 19 & 37.3 & 0 & 32 & 62.8 & 1 \\
\hline BMI before pregnancy $\left(\mathrm{kg} / \mathrm{m}^{2}\right)$ & & & 40 & & & 16 & & & 24 & & & 0 \\
\hline Median & & & & & 3.2 & & & 1 & & & .5 & \\
\hline Q1-Q3 & 20 . & $25 \cdot 4$ & & 21. & $-25 \cdot 7$ & & 21 . & $-25 \cdot 8$ & & & $-23 \cdot 8$ & \\
\hline BMI near term $\left(\mathrm{kg} / \mathrm{m}^{2}\right)$ & & & 11 & & & 2 & & & 9 & & & 0 \\
\hline $\begin{array}{l}\text { Median } \\
\text { Q1-Q3 }\end{array}$ & 25. & $\begin{array}{l}0 \\
30 \cdot 8\end{array}$ & & 25 . & $\begin{array}{l}.9 \\
-30 \cdot 9\end{array}$ & & 25. & $\begin{array}{l}.4 \\
-30 \cdot 7\end{array}$ & & & $\begin{array}{l}3 \cdot 0 \\
-30 \cdot 1\end{array}$ & \\
\hline BW gain during pregnancy $(\mathrm{kg})$ & & & 42 & & & 19 & & & 23 & & & 0 \\
\hline $\begin{array}{l}\text { Mean } \\
\text { SD }\end{array}$ & & & & & $\begin{array}{l}3.4 \\
7\end{array}$ & & & 7 & & & $\cdot 3$ & \\
\hline Skin colour & & & 6 & & & 1 & & & 5 & & & 0 \\
\hline Light & 265 & $86 \cdot 9$ & & 173 & $85 \cdot 2$ & & 44 & $86 \cdot 3$ & & 48 & $94 \cdot 1$ & \\
\hline Dark & 34 & 11.2 & & 29 & 14.3 & & 2 & 3.9 & & 3 & 5.9 & \\
\hline Country of origin & & & 4 & & & 2 & & & 2 & & & 0 \\
\hline Group 1 & 109 & $35 \cdot 7$ & & 67 & 33.0 & & 21 & $41 \cdot 2$ & & 21 & 41.2 & \\
\hline Group 2 & 74 & $24 \cdot 3$ & & 62 & 30.5 & & 7 & 13.7 & & 5 & 9.8 & \\
\hline Group 3 & 72 & 23.6 & & 30 & $14 \cdot 8$ & & 18 & $35 \cdot 3$ & & 24 & $47 \cdot 1$ & \\
\hline Group 4 & 21 & 6.9 & & 18 & 8.9 & & 2 & 3.9 & & 1 & $2 \cdot 0$ & \\
\hline Group 5 & 25 & 8.2 & & 24 & 11.8 & & 1 & $2 \cdot 0$ & & 0 & 0 & \\
\hline Education & & & 30 & & & 19 & & & 5 & & & 6 \\
\hline Less than compulsory & 12 & 3.9 & & 9 & 4.4 & & 0 & 0 & & 3 & 5.9 & \\
\hline Compulsory & 50 & $16 \cdot 4$ & & 30 & 14.8 & & 7 & 13.7 & & 13 & 25.5 & \\
\hline Secondary & 111 & $36 \cdot 4$ & & 62 & 30.5 & & 27 & 52.9 & & 22 & 43.1 & \\
\hline Tertiary & 102 & 33.4 & & 83 & 40.9 & & 12 & 23.5 & & 7 & 13.7 & \\
\hline Education of the partner & & & 40 & & & 27 & & & 7 & & & 6 \\
\hline Less than compulsory & 15 & 4.9 & & 11 & 5.4 & & 1 & $2 \cdot 0$ & & 3 & 5.9 & \\
\hline Compulsory & 37 & $12 \cdot 1$ & & 18 & 8.9 & & 6 & 11.8 & & 13 & 25.5 & \\
\hline Secondary & 112 & $36 \cdot 7$ & & 62 & 30.5 & & 26 & 51.0 & & 24 & $47 \cdot 1$ & \\
\hline Tertiary & 101 & 33.1 & & 85 & 41.9 & & 11 & 21.6 & & 5 & 9.8 & \\
\hline Smoking status & & & 2 & & & 1 & & & 1 & & & 0 \\
\hline Never & 187 & 61.3 & & 122 & 60.1 & & 32 & $62 \cdot 8$ & & 33 & 64.7 & \\
\hline Ever & 89 & 29.2 & & 61 & 30.1 & & 14 & 27.5 & & 14 & 27.5 & \\
\hline Current & 27 & $8 . \overline{9}$ & & 19 & 9.4 & & 4 & 7.8 & & 4 & 7.8 & \\
\hline Season & & & 0 & & & 0 & & & 0 & & & 0 \\
\hline Winter & 78 & $25 \cdot 6$ & & 65 & 32.0 & & 11 & 21.6 & & 2 & 3.9 & \\
\hline Spring & 107 & 35.1 & & 79 & 38.9 & & 10 & $19 \cdot 6$ & & 18 & 35.3 & \\
\hline Summer & 39 & $12 \cdot 8$ & & 20 & 9.9 & & 11 & 21.6 & & 8 & $15 \cdot 7$ & \\
\hline Autumn & 81 & $26 \cdot 6$ & & 39 & 19.21 & & 19 & 37.3 & & 23 & $45 \cdot 1$ & \\
\hline $\begin{array}{l}\text { Days per week spent at least } 1 \mathrm{~h} \\
\text { outdoor in the past } 6 \text { months }\end{array}$ & & & 15 & & & 5 & & & 5 & & & 5 \\
\hline Median & & & & & 4 & & & 6 & & & & \\
\hline Q1-Q3 & & & & & -7 & & & -7 & & & & \\
\hline Using sun protection in summer & & & 3 & & & 1 & & & 1 & & & 1 \\
\hline Never & 51 & $16 \cdot 7$ & & 42 & 20.7 & & 7 & 13.7 & & 2 & 3.9 & \\
\hline Sometimes & 130 & 42.6 & & 81 & 39.9 & & 25 & $49 \cdot 0$ & & 24 & $47 \cdot 1$ & \\
\hline Always & 121 & 39.7 & & 79 & 38.9 & & 18 & $35 \cdot 3$ & & 24 & $47 \cdot 1$ & \\
\hline Fish consumption at least once a week & 184 & $60 \cdot 3$ & 6 & 109 & 53.7 & 2 & 37 & $72 \cdot 6$ & 2 & 38 & 74.5 & 2 \\
\hline Vitamin D supplement intake & 216 & $70 \cdot 8$ & 0 & 165 & $81 \cdot 3$ & 0 & 21 & $41 \cdot 2$ & 0 & 30 & $58 \cdot 8$ & 0 \\
\hline
\end{tabular}

25(OH)D, 25-hydroxyvitamin D; BW, body weight.

* Skin colour was dichotomised in light (Fitzpatrick levels I to III) or dark colour (Fitzpatrick levels IV and V). Country groups are as follows: group 1, Switzerland and Germany; group 2, Northern America, Northern Europe, Central Asia and New Zealand; group 3, Southern Europe, Australia and Latin America; group 4, South and East Asia and Pacific; and group 5, Africa and Middle East. Seasons were defined as follows: winter (21 December-20 March), spring (21 March-20 June), summer (21 June-20 September) and autumn (21 September-20 December). 
(a)

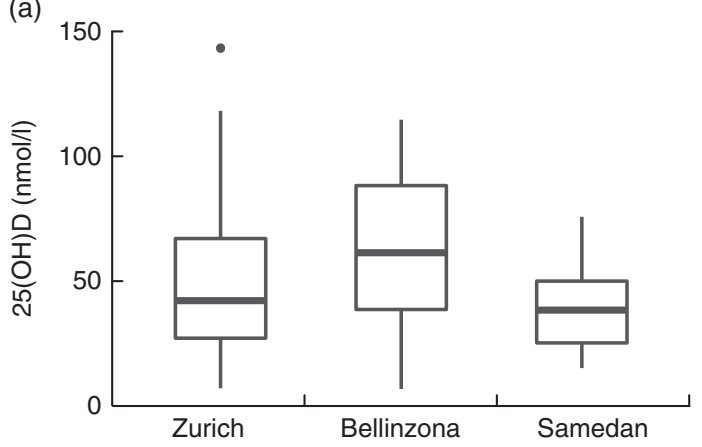

(c)

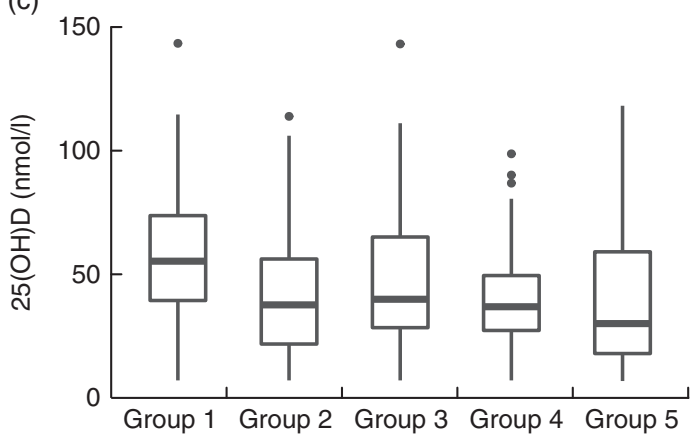

(b)

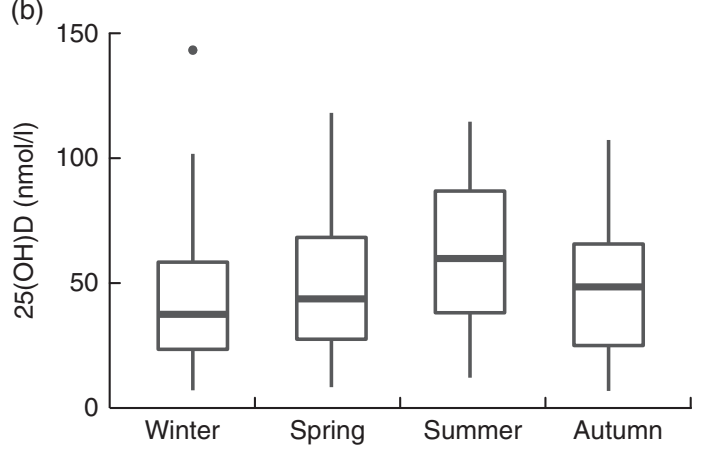

(d)

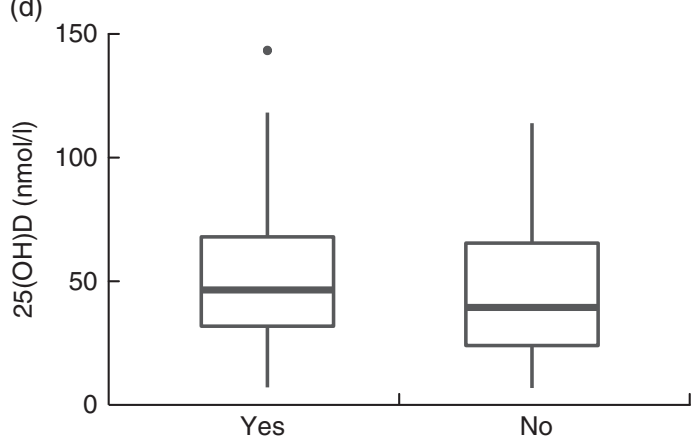

(e)

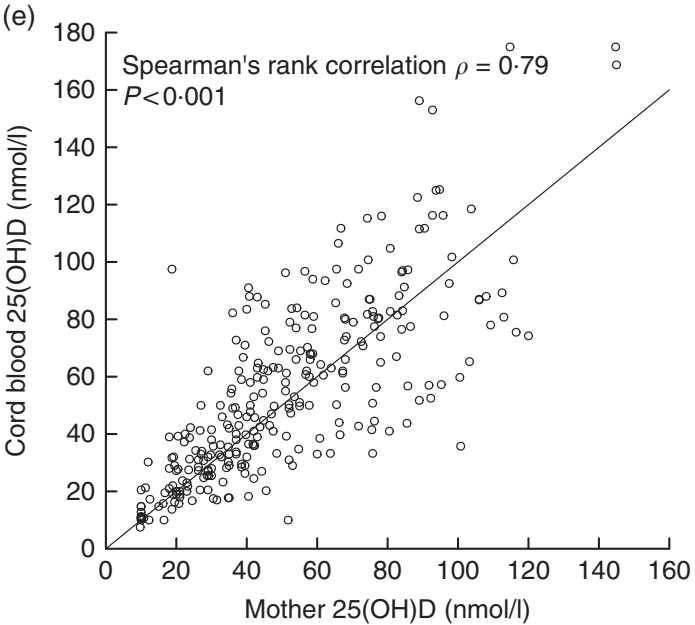

Fig. 2. Serum 25-hydroxyvitamin D (25(OH)D) levels in pregnant women by (a) study centre, (b) season of delivery, (c) country of origin and (d) intake of vitamin D supplements. (e) Correlation between serum 25(OH)D concentration of pregnant women and the umbilical cord blood of their neonates ( $n$ 283). Country groups are as follows: group 1, Switzerland and Germany; group 2, Northern America, Northern Europe, Central Asia and New Zealand; group 3, Southern Europe, Australia and Latin America; group 4, South and East Asia and Pacific; and group 5, Africa and Middle East. Seasons were defined as follows: winter (21 December-20 March), spring (21 March-20 June), summer (21 June-20 September) and autumn (21 September-20 December).

determinants (centre, country of origin, season and use of vitamin D supplements) can be markedly improved by the addition of further four variables (BMI near term, skin colour, education of the mother, use of sunscreen).

\section{Discussion}

Vitamin D deficiency during pregnancy has been linked with several adverse health outcomes. Therefore, the fact that low serum levels were repeatedly found in pregnant women from different countries and at different stages of pregnancy is a matter of concern ${ }^{(3,15)}$. The prevalence and determinants of vitamin D inadequacy, however, seem to vary with the population studied ${ }^{(1,15)}$. Hence, to address the needs of the local population, it is therefore crucial to understand the country-specific determinants of vitamin $\mathrm{D}$ deficiency. To the best of our knowledge, our study is the first to investigate the prevalence and determinants of vitamin $\mathrm{D}$ deficiency in women living in Switzerland during the last trimester of pregnancy, and to measure $25(\mathrm{OH}) \mathrm{D}$ in the cord blood of their newborns. Beyond the local value of this information, our data may be of interest for other European countries because of 
Table 2. Vitamin $D$ deficiency during pregnancy in the studied sample ( $n$ 305), results of univariable and multivariable logistic regressions* (Odds ratios and $95 \%$ confidence intervals)

\begin{tabular}{|c|c|c|c|c|c|c|c|c|}
\hline & \multicolumn{2}{|c|}{ Univariable models } & \multicolumn{2}{|c|}{ Multivariable model 1} & \multicolumn{2}{|c|}{ Multivariable model 2} & \multicolumn{2}{|c|}{ Multivariable model 3} \\
\hline & OR & $95 \% \mathrm{Cl}$ & OR & $95 \% \mathrm{Cl}$ & OR & $95 \% \mathrm{Cl}$ & OR & $95 \% \mathrm{Cl}$ \\
\hline \multicolumn{9}{|l|}{ Centre } \\
\hline Zurich & 1 & Ref. & 1 & Ref. & 1 & Ref. & 1 & Ref. \\
\hline Bellinzona & 0.41 & $0.22,0.79$ & 0.29 & $0.11,0.78$ & 0.36 & $0.16,0.80$ & 0.40 & $0.19,0.86$ \\
\hline Samedan & 1.81 & $0.94,3.49$ & $2 \cdot 48$ & $1.04,5.89$ & 2.49 & $1 \cdot 12,5.55$ & 2.72 & $1.27,5.83$ \\
\hline Age (years) & 0.96 & $0.92,1.01$ & 0.98 & $0.92,1.03$ & - & - & - & - \\
\hline Week of pregnancy & 0.93 & $0.76,1.13$ & $1 \cdot 12$ & $0.85,1.49$ & - & - & - & - \\
\hline Nulliparity & 0.92 & $0.58,1.46$ & - & - & - & - & - & - \\
\hline First pregnancy & 0.78 & $0.48,1.25$ & 0.75 & $0.41,1.37$ & - & - & - & - \\
\hline BMI before pregnancy $\left(\mathrm{kg} / \mathrm{m}^{2}\right)$ & 1.05 & $1.00,1.11$ & - & - & - & - & - & - \\
\hline BMI near term $\left(\mathrm{kg} / \mathrm{m}^{2}\right)$ & 1.07 & $1.02,1.13$ & 1.04 & $0.98,1.11$ & 1.05 & $0.99,1.11$ & - & - \\
\hline BW gain during pregnancy $(\mathrm{kg})$ & 1.02 & $0.98,1.06$ & 1.01 & $0.96,1.07$ & - & - & - & - \\
\hline \multicolumn{9}{|l|}{ Skin colour } \\
\hline Light & 1 & Ref. & 1 & Ref. & 1 & Ref. & - & - \\
\hline Dark & $1 \cdot 27$ & $0.61,2 \cdot 60$ & 0.39 & $0.14,1.12$ & 0.41 & $0.15,1.12$ & & \\
\hline \multicolumn{9}{|l|}{ Country of origin } \\
\hline Group 1 & 1 & Ref. & 1 & Ref. & 1 & Ref. & 1 & Ref. \\
\hline Group 2 & $2 \cdot 73$ & $1.48,5.03$ & $2 \cdot 33$ & $1.15,4.73$ & 2.40 & $1.21,4.75$ & 2.99 & $1.56,5 \cdot 74$ \\
\hline Group 3 & $2 \cdot 34$ & $1.27,4.30$ & $2 \cdot 41$ & $1 \cdot 14,5 \cdot 11$ & $2 \cdot 21$ & $1.08,4.52$ & $2 \cdot 37$ & $1.22,4.61$ \\
\hline Group 4 & $4 \cdot 32$ & $1.55,12.03$ & $7 \cdot 27$ & $1.92,27.55$ & 7.81 & $2 \cdot 16,28 \cdot 23$ & 5.63 & $1.85,17 \cdot 15$ \\
\hline Group 5 & 3.53 & $1.40,8.89$ & 4.86 & $1.40,16.85$ & 4.74 & $1.43,15.77$ & 4.50 & $1.68,12.07$ \\
\hline \multicolumn{9}{|l|}{ Education } \\
\hline Less than compulsory & 1 & Ref. & 1 & Ref. & 1 & Ref. & - & - \\
\hline Compulsory & 0.85 & $0.20,3.53$ & 0.86 & $0.18,4.00$ & 0.95 & $0.21,4.30$ & - & - \\
\hline Secondary & 0.46 & $0.12,1.75$ & 0.67 & $0.16,2.85$ & 0.66 & $0.16,2.77$ & - & - \\
\hline Tertiary & 0.26 & $0.07,0.98$ & 0.39 & $0.09,1.69$ & 0.39 & $0.10,1.58$ & - & - \\
\hline \multicolumn{9}{|l|}{ Education of the partner } \\
\hline Less than compulsory & 1 & Ref. & - & - & - & - & - & - \\
\hline Compulsory & 0.6 & $0.14,2.55$ & - & - & - & - & - & - \\
\hline Secondary & 0.38 & $0.10,1 \cdot 40$ & - & - & - & - & - & - \\
\hline Tertiary & 0.19 & $0.05,0.72$ & - & - & - & - & - & - \\
\hline \multicolumn{9}{|l|}{ Smoking status } \\
\hline Never & 1 & Ref. & 1 & Ref. & - & - & - & - \\
\hline Ever & 0.84 & $0.50,1.39$ & 0.92 & $0.50,1.69$ & - & - & - & - \\
\hline Current & 1.43 & $0.62,3.30$ & 1.07 & $0.40,2.90$ & - & - & - & - \\
\hline \multicolumn{9}{|l|}{ Season } \\
\hline Winter & 1 & Ref. & 1 & Ref. & 1 & Ref. & 1 & Ref. \\
\hline Spring & 0.7 & $0.38,1.27$ & 0.73 & $0.36,1.45$ & 0.74 & $0.37,1.46$ & 0.64 & $0.33,1.23$ \\
\hline Summer & 0.41 & $0.19,0.91$ & 0.33 & $0.13,0.86$ & 0.33 & $0.13,0.84$ & 0.31 & $0.13,0.75$ \\
\hline Autumn & 0.58 & $0.31,1.09$ & 0.45 & $0.20,0.98$ & 0.40 & $0.19,0.86$ & 0.40 & $0.19,0.83$ \\
\hline $\begin{array}{l}\text { Days per week spent at least } 1 \mathrm{~h} \text { outdoor } \\
\text { in the past } 6 \text { months }\end{array}$ & 0.97 & $0.89,1.07$ & 0.97 & $0.87,1.08$ & - & - & - & - \\
\hline \multicolumn{9}{|l|}{ Using sun protection in summer } \\
\hline Never & 1 & Ref. & 1 & Ref. & 1 & Ref. & - & - \\
\hline Sometimes & 0.38 & $0.19,0.77$ & 0.47 & $0.20,1.10$ & 0.44 & $0.20,1.00$ & - & - \\
\hline Always & 0.38 & $0.19,0.78$ & 0.61 & $0.25,1.50$ & 0.57 & $0.24,1.32$ & - & - \\
\hline Fish consumption at least once a week & 0.9 & $0.56,1.44$ & 0.85 & $0.47,1.52$ & - & - & - & - \\
\hline Vitamin D supplement intake & 0.66 & $0.40,1.09$ & 0.42 & $0.22,0.80$ & 0.42 & $0.22,0.80$ & 0.43 & $0.23,0.79$ \\
\hline
\end{tabular}

Ref., referent values; BW, body weight.

* Multivariable model 1 was adjusted for study centre, age, week of pregnancy, first pregnancy, BMI near term, BW gained during pregnancy, skin colour, country of origin, education level achieved by the mother, smoking status, season of delivery, days per week spent at least $1 \mathrm{~h}$ outdoor in the past 6 months, use of sun protection in the summer, fish consumption and intake of vitamin D-containing supplements. Model 2 was adjusted for study centre, BMI near term, skin colour, country of origin, education level achieved by the mother, season of delivery, use of sun protection in the summer and intake of vitamin D-containing supplements. Model 3 was adjusted for study centre, country of origin, season of delivery and intake of vitamin D-containing supplements. Country groups are as follows: group 1, Switzerland and Germany; group 2, Northern America, Northern Europe, Central Asia and New Zealand; group 3, Southern Europe, Australia and Latin America; group 4, South and East Asia and Pacific; and group 5, Africa and Middle East. Seasons were defined as follows: winter (21 December-20 March), spring (21 March-20 June), summer (21 June-20 September) and autumn (21 September-20 December).

Switzerland's specific blend of cultural and meteorological influences.

Data from our multicentre study indicate an overall prevalence of vitamin D deficiency of $53 \%$ among women in the third trimester of pregnancy in Switzerland. This overall prevalence is somewhat comparable with the prevalence reported in neighbouring countries, such as Germany $\left(77 \%{ }^{(32)}\right)$, Northern Italy $\left(85 \%{ }^{(33)}\right)$ or France $\left(41 \%^{(34)}\right)$. More broadly, our results lie within the wide range of reported prevalence rates of vitamin D deficiency during pregnancy, whether the investigated populations are located in the Mediterranean region $\left(22 \cdot 7-90 \cdot 3 \%^{(20)}\right.$ ) or in the North of Europe (Belgium $45 \%{ }^{(35)}$, Finland $60 \%{ }^{(36)}$, Sweden $\left.65 \%{ }^{(17)}\right)$.

Interestingly, in Switzerland, non-pregnant women showed a much lower all-year prevalence of vitamin D deficiency than the one reported here in pregnant women $\left(35 \%{ }^{(37)}\right)$. Data directly comparing the vitamin D status of pregnant women with women of procreating age are scarce. Ritchie et $a l .^{(38)}$ 
Model 1

(full)
Model 2 (intermediate)
Model 3

(core) (a)

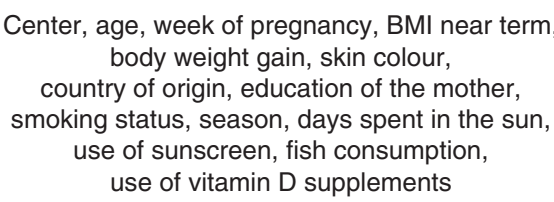

Center, age, week of pregnancy, BMI near term body weight gain, skin colour, country of origin, education of the mother, smoking status, season, days spent in the sun, use of sunscreen, fish consumption, use of vitamin D supplements

(b)

$\mathrm{AIC}=298.58$

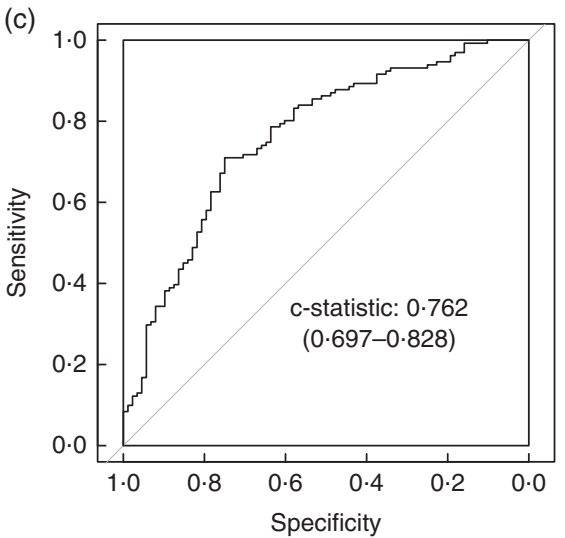

(d)

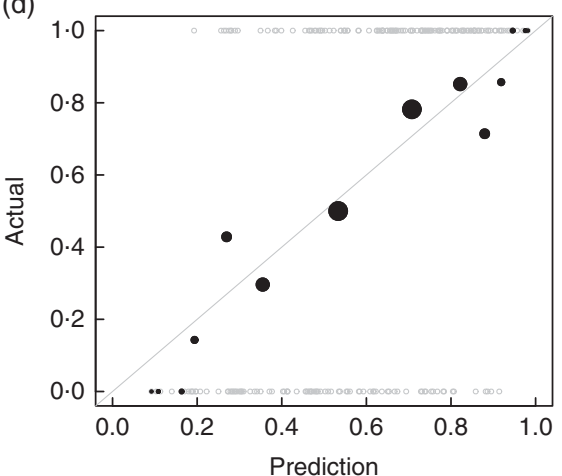

Center, BMI near term, skin colour, country of origin, season, education of the mother, use of suncreen, use of vitamin $\mathrm{D}$ supplements

Fig. 3. (a) Variables included, (b) Akaike information criterion (AIC), (c) receiver operating characteristic curves and (d) observed $v$. predicted value plots in all three logistic regression models. Model diagnostics were computed on complete cases common to the tree models $(n 219)$.

reported no significant differences in $25(\mathrm{OH}) \mathrm{D}$ measured in fourteen women before pregnancy, during each trimester and during lactation. Some data, however, indicate that the $25(\mathrm{OH})$ $\mathrm{D}$ concentrations in early pregnancy do not differ from those of non-pregnant women, but exhibit a significant decrease towards the end of pregnancy ${ }^{(39-41)}$. Several mechanisms could explain this decrease in $25(\mathrm{OH}) \mathrm{D}$ during pregnancy. First, 25 $(\mathrm{OH}) \mathrm{D}$ passes the placenta and the fetus is completely dependent on the maternal serum for vitamin D supply. The lower serum $25(\mathrm{OH}) \mathrm{D}$ of the mother could therefore reflect the placetal transfer to the growing fetus. Moreover, plasma parathyroid hormone increases during pregnancy, thus potentially explaining the decrease in $25(\mathrm{OH}) \mathrm{D}$ during pregnancy ${ }^{(39)}$. Finally, certain authors hypothesised that the liver hydroxylation of vitamin D may be affected by pregnancy ${ }^{(40)}$, because the modulation of different types of cytochrome $\mathrm{P} 450$ has been reported $^{(42)}$.
Furthermore, the prevalence of $25(\mathrm{OH}) \mathrm{D}$ concentrations below $50 \mathrm{nmol} / 1$ in the cord blood of newborns (49.8\%) is comparable with the prevalence of vitamin D deficiency in mothers $(53.4 \%)$. This strong correlation corroborates with the numerous reports that concentrations of $25(\mathrm{OH}) \mathrm{D}$ in the cord blood at delivery correlate with those of the mothers ${ }^{(7-10)}$, although the reported correlation coefficient does vary markedly between studies. Knowing the risk of disturbed fetal development, as well as diseases occurring later in life (diabetes, asthma) $^{(4)}$, the high prevalence of vitamin D deficiency in mothers and newborns is alarming.

An interesting feature of our study is the varying prevalence of vitamin D deficiency between the study centres $(55 \%$ in Zurich, 33\% in Bellinzona, 69\% in Samedan). Hence, the specific study centre (which is a proxy for the region in which women lived) was a strong determinant of vitamin D deficiency - that is a variable found in all logistic regression models. 
Socio-demographic determinants are unlikely to explain the different prevalence of vitamin D deficiency across centres, because Samedan and Bellinzona showed similar population characteristics (Table 1). Diversity of diets across centres may be a plausible cause, but our data on fish consumption, a major nutritional source of vitamin $\mathrm{D}$, indicate similar consumption levels in Samedan and Bellinzona. Vitamin D intake, however, was not measured in our study, and this hypothesis cannot be fully discounted. Nevertheless, the most likely cause is the fact that differences in sunshine duration and outdoor temperature drive very diverse skin exposure time to UVB between the three centres (Fig. 1(b)).

The intake of vitamin D-containing supplements (alone or as a multivitamin supplement) protected against vitamin $\mathrm{D}$ deficiency. The consumption of fish, however, was not a significant determinant of vitamin D deficiency. Here, we assessed fish consumption based on studies showing that fish and seafood are the main sources of dietary vitamin $\mathrm{D}$ in pregnant women and reflect the total dietary vitamin $\mathrm{D}$ intake ${ }^{(18)}$. Therefore, our findings are in accordance with studies showing that high vitamin $\mathrm{D}$ intake is mostly achieved by supplement intake rather than through diet ${ }^{(18)}$. These data further advocate for vitamin D supplementation during pregnancy. In support of this, several randomised control trials consistently showed that vitamin D supplements were effective in increasing maternal 25 $(\mathrm{OH}) \mathrm{D}$ concentrations at term ${ }^{(6)}$, umbilical cord venous and neonatal serum $25(\mathrm{OH}) \mathrm{D}$ as compared with a placebo ${ }^{(43-45)}$.

Paradoxically, in our sample population, a high percentage of vitamin D supplement or multivitamin supplement intake (71\%) did not prevent a high prevalence of vitamin D deficiency. This paradox may be explained by an inadequate or insufficient intake of vitamin $\mathrm{D}$, despite the wide use of supplements. Indeed, in our study, we did not quantitatively evaluate vitamin D intake. Similarly, in a large sample of pregnant women from Denmark, only $30 \%$ of the population had an adequate vitamin $\mathrm{D}$ intake (defined by a daily intake of $10 \mu \mathrm{g} / \mathrm{d}$ - maximum reached after 30 weeks of pregnancy), whereas the majority of women $(67.5 \%)$ took vitamin D supplements $^{(18)}$. In addition, the type of vitamin D supplements reported was highly diverse (data not shown): brands, doses, single substance $v$. multivitamin mixes, countries of manufacture were the main factors of supplements heterogeneity. This indicates that, despite the existence of Swiss guidelines (600 IU (15 mg) vitamin D/d and 1500-2000 IU (37.5-50 mg) when deficiency is evident $\left.{ }^{(46)}\right)$, vitamin $\mathrm{D}$ intake during pregnancy remains partly inadequate. Further advice from medical practitioners may help women to choose adequate supplements and use them appropriately. However, even in the presence of a standardised vitamin D supplementation, the heterogeneity of $25(\mathrm{OH}) \mathrm{D}$ response to vitamin $\mathrm{D}$ supplementation has been documented ${ }^{(47-49)}$ and includes genetic factors, BMI and baseline 25(OH)D levels. Therefore, this indicates that a successful vitamin $\mathrm{D}$ supplementation plan would also require individualisation on the basis of serum 25 $(\mathrm{OH}) \mathrm{D}$ measurement during pregnancy.

The comparative analysis of several logistic regression models allowed us to systematically test the relative importance of vitamin D determinants included in this study. Thus, we identified four core determinants of vitamin D deficiency (centre of study, country of origin, season of delivery, intake of vitamin D supplements), as well as four secondary factors (factors not reaching significance individually but improving the goodness of fit of the model: education, near-term BMI, skin colour, use of sunscreen). The regression models, however, should not be considered as an attempt to find prediction formula for vitamin D deficiency in pregnant women in Switzerland. Indeed, the nature of our experimental design does not make these models suitable for prediction: first, only one data set was available and used for the establishment of these models, thus leaving no data available for external model validation. Second, the sample in this study was not designed to be representative of the Swiss population; consequently, the relevance of the models presented here is limited to our sample. In addition, owing to the use of a multiple imputation strategy, the diagnostics of the models were limited. Eventually, we acknowledge that other potential determinants of vitamin D levels, such as nutritional intake, physical activity or genetic background, were not optimally investigated here and should be the objective of future studies.

In conclusion, our study was the first to our knowledge to address prevalence rates of vitamin D deficiency in late pregnancy in Switzerland. This study indicated that low vitamin D levels are common in this sample of pregnant women living in Switzerland, as well as in their neonates' cord blood. Using logistic regression analyses and model comparison, we identified the centre of study, country of origin, season of delivery and intake of vitamin D supplements as main determinants of vitamin $\mathrm{D}$ deficiency in pregnant women. As the intake of vitamin D supplement is the most likely actionable determinant identified in this study, it suggests that vitamin D supplementation during pregnancy should receive more attention in clinical practice.

\section{Acknowledgements}

The authors thank Dr Sarah Haile (University of Zurich) for statistical support, Nina Pupikofer (National Institute for Cancer Epidemiology and Registration) for data entry, Dr Kelly Turner for language check and editing suggestions, Dr Marco Cantú (Biochemistry and Pharmacology Laboratory, Hospital of Bellinzona) and Dr Massimo Locatelli (San Raffaele Hospital) for assistance in sample analysis and data interpretation and all women who participated in this study. The authors thank the Swiss Federal Office of Meteorology and Climatology MeteoSwiss for providing summary weather data.

This work was supported by the Swiss National Science Foundation: NRP69 grant 4069-145194.

J.-P. K. analysed data and wrote the paper. S. C. and A. R. analysed data, and edited and reviewed the manuscript. C. C., L. C., T. S. and B. L. W. provided essential materials and conducted research (recruiting and sample collection). S. R. and K. Q. L. designed research, conducted research (recruiting and sample collection), edited and reviewed the manuscript and had primary responsibility for final content. All authors have read and approved the final manuscript.

None of the authors has any conflicts of interest to declare. 


\section{References}

1. Hilger J, Friedel A, Herr R, et al. (2014) A systematic review of vitamin D status in populations worldwide. Br J Nutr 111, 23-45.

2. Palacios C \& Gonzalez L (2014) Is vitamin D deficiency a major global public health problem? J Steroid Biochem Mol Biol 144, 138-145.

3. Dror DK \& Allen LH (2010) Vitamin D inadequacy in pregnancy: biology, outcomes, and interventions. Nutr Rev 68, 465-477.

4. Moon RJ, Harvey NC \& Cooper C (2015) Endocrinology in pregnancy: Influence of maternal vitamin D status on obstetric outcomes and the fetal skeleton. Eur J Endocrinol 173, 69-83.

5. Harvey NC, Holroyd C, Ntani G, et al. (2014) Vitamin D supplementation in pregnancy: a systematic review. Health Technol Assess 18, 1-190.

6. De-Regil LM, Palacios C, Lombardo LK, et al. (2016) Vitamin D supplementation for women during pregnancy. Cochrane Database Syst Rev, issue 1, CD008873.

7. Bodnar LM, Catov JM, Roberts JM, et al. (2007) Prepregnancy obesity predicts poor vitamin D status in mothers and their neonates. J Nutr 137, 2437-2442.

8. Wegienka G, Kaur H, Sangha R, et al. (2016) Maternal-cord blood vitamin D correlations vary by maternal levels. J Pregnancy 2016, 7474192.

9. Markestad T, Aksnes L, Ulstein M, et al. (1984) 25-Hydroxyvitamin $\mathrm{D}$ and 1,25-dihydroxyvitamin $\mathrm{D}$ of $\mathrm{D}_{2}$ and $\mathrm{D}_{3}$ origin in maternal and umbilical cord serum after vitamin $\mathrm{D}_{2}$ supplementation in human pregnancy. Am J Clin Nutr 40, 1057-1063.

10. Maghbooli Z, Hossein-Nezhad A, Shafaei AR, et al. (2007) Vitamin D status in mothers and their newborns in Iran. BMC Pregnancy Childbirth 7, 1.

11. Bassir M, Laborie S, Lapillonne A, et al. (2001) Vitamin D deficiency in Iranian mothers and their neonates: a pilot study. Acta Paediatr 90, 577-579.

12. Bodnar LM, Simhan HN, Powers RW, et al. (2007) High prevalence of vitamin $\mathrm{D}$ insufficiency in black and white pregnant women residing in the northern United States and their neonates. J Nutr 137, 447-452.

13. Holmes VA, Barnes MS, Alexander HD, et al. (2009) Vitamin D deficiency and insufficiency in pregnant women: a longitudinal study. Br J Nutr 102, 876-881.

14. Molla AM, Badawi Al M, Hammoud MS, et al. (2005) Vitamin D status of mothers and their neonates in Kuwait. Pediatr Int 47, 649-652.

15. Ponsonby A-L, Lucas RM, Lewis S, et al. (2010) Vitamin D status during pregnancy and aspects of offspring health. Nutrients 2, 389-407.

16. Saraf R, Morton SMB, Camargo CAJ, et al. (2016) Global summary of maternal and newborn vitamin D status - a systematic review. Matern Child Nutr 12, 647-668.

17. Brembeck P, Winkvist A \& Olausson H (2013) Determinants of vitamin D status in pregnant fair-skinned women in Sweden. Br J Nutr 110, 856-864.

18. Jensen CB, Petersen SB, Granstrom C, et al. (2012) Sources and determinants of vitamin $\mathrm{D}$ intake in Danish pregnant women. Nutrients $\mathbf{4}, 259-272$.

19. Richard A, Rohrmann S \& Quack Lötscher KC (2017) Prevalence of vitamin $\mathrm{D}$ deficiency and its associations with skin color in pregnant women in the first trimester in a sample from Switzerland. Nutrients 9, 260.

20. Karras S, Paschou SA, Kandaraki E, et al. (2016) Hypovitaminosis $\mathrm{D}$ in pregnancy in the Mediterranean region: a systematic review. Eur J Clin Nutr 70, 979-986.

21. Rodriguez A, Santa Marina L, Jimenez AM, et al. (2016) Vitamin D status in pregnancy and determinants in a Southern European Cohort Study. Paediatr Perinat Epidemiol 30, 217-228.
22. Dovnik A, Mujezinović F, Treiber M, et al. (2017) Determinants of maternal vitamin $\mathrm{D}$ concentrations in Slovenia: a prospective observational study. Wien Klin Wochenschr 129, 21-28.

23. Zgaga L, Agakov F, Theodoratou E, et al. (2013) Model Selection Approach Suggests Causal Association between 25-Hydroxyvitamin D and Colorectal Cancer. PLOS ONE $\mathbf{8}$, e63475.

24. Sohl E, Heymans MW, de Jongh RT, et al. (2014) Prediction of vitamin D deficiency by simple patient characteristics. Am J Clin Nutr 99, 1089-1095.

25. Federal Statistical Office (2017) Statistical Atlas of Switzerland., https://www.atlas.bfs.admin.ch (accessed October 2017).

26. Agresti A (2007) An Introduction to Categorical Data Analysis, 2nd ed. Hoboken, NJ: John Wiley \& Sons.

27. Holick MF, Binkley NC, Bischoff-Ferrari HA, et al. (2011) Evaluation, treatment, and prevention of vitamin D deficiency: an Endocrine Society clinical practice guideline. J Clin Endocrinol Metab 96, 1911-1930.

28. Dawson-Hughes B, Mithal A, Bonjour J-P, et al. (2010) IOF position statement: vitamin $\mathrm{D}$ recommendations for older adults. Osteoporos Int 21, 1151-1154.

29. Hanley DA, Cranney A, Jones G, et al. (2010) Vitamin D in adult health and disease: a review and guideline statement from Osteoporosis Canada. CMAJ 182, E610-E618.

30. Fitzpatrick TB (1988) The validity and practicality of sunreactive skin types I through VI. Arch Dermatol 124, 869-871.

31. Buuren SV \& Groothuis-Oudshoorn K (2011) mice: multivariate imputation by chained equations in R. J Stat Software 45, 1-67.

32. Wuertz C, Gilbert P, Baier W, et al. (2013) Cross-sectional study of factors that influence the 25-hydroxyvitamin D status in pregnant women and in cord blood in Germany. Br J Nutr 110, 1895-1902.

33. Cadario F, Savastio S, Magnani C, et al. (2015) High prevalence of vitamin $\mathrm{D}$ deficiency in native versus migrant mothers and newborns in the north of Italy: a call to act with a stronger prevention program. PLOS ONE 10, e0129586.

34. Ceccaldi P-F, Pejoan H, Breau N, et al. (2017) French prenatal Vitamin D recommended supplementation: Enough or not? J Gynecol Obstet Biol Reprod 46, 35-41.

35. Vandevijvere S, Amsalkhir S, Van Oyen H, et al. (2012) High prevalence of vitamin D deficiency in pregnant women: a national cross-sectional survey. PLOS ONE 7, e43868.

36. Viljakainen HT, Saarnio E, Hytinantti T, et al. (2010) Maternal vitamin D status determines bone variables in the newborn. J Clin Endocrinol Metab 95, 1749-1757.

37. Guessous I, Dudler V, Glatz N, et al. (2012) Vitamin D levels and associated factors: a population-based study in Switzerland. Swiss Med Wkly 142, w13719.

38. Ritchie LD, Fung EB, Halloran BP, et al. (1998) A longitudinal study of calcium homeostasis during human pregnancy and lactation and after resumption of menses. Am J Clin Nutr $\mathbf{6 7}$, 693-701.

39. Ardawi MS, Nasrat HA \& BA'Aqueel HS (1997) Calciumregulating hormones and parathyroid hormone-related peptide in normal human pregnancy and postpartum: a longitudinal study. Eur J Endocrinol 137, 402-409.

40. Salle BL, Delvin EE, Lapillonne A, et al. (2000) Perinatal metabolism of vitamin D. Am J Clin Nutr 71, 1317S-1324SS.

41. Zhang JY, Lucey AJ, Horgan R, et al. (2014) Impact of pregnancy on vitamin D status: a longitudinal study. BrJ Nutr 112, 1081-1087.

42. Anderson GD (2005) Pregnancy-induced changes in pharmacokinetics. Clin Pharmacokinet 44, 989-1008. 
43. Hollis BW, Johnson D, Hulsey TC, et al. (2011) Vitamin D supplementation during pregnancy: double-blind, randomized clinical trial of safety and effectiveness. J Bone Miner Res 26, 2341-2357.

44. Wagner CL, McNeil RB, Johnson DD, et al. (2013) Health characteristics and outcomes of two randomized vitamin D supplementation trials during pregnancy: a combined analysis. J Steroid Biochem Mol Biol 136, 313-320.

45. Dawodu A, Saadi HF, Bekdache G, et al. (2013) Randomized controlled trial (RCT) of vitamin D supplementation in pregnancy in a population with endemic vitamin D deficiency. J Clin Endocrinol Metab 98, 2337-2346.

46. Quack Lötscher KC, l'Allemand D, Bischoff-Ferrari HA, et al. (2012) Vitamin D Deficiency: Evidence, Safety, and
Recommendations for the Swiss Population. Switzerland: Federal Office of Public Health.

47. Fu L, Yun F, Oczak M, et al. (2009) Common genetic variants of the vitamin D binding protein (DBP) predict differences in response of serum 25-hydroxyvitamin D [25(OH)D] to vitamin D supplementation. Clin Biochem 42, 1174-1177.

48. Didriksen A, Grimnes G, Hutchinson MS, et al. (2013) The serum 25-hydroxyvitamin D response to vitamin D supplementation is related to genetic factors, BMI, and baseline levels. Eur J Endocrinol 169, 559-567.

49. Moon RJ, Harvey NC, Cooper C, et al. (2016) Determinants of the maternal 25-hydroxyvitamin $\mathrm{D}$ response to vitamin $\mathrm{D}$ supplementation during pregnancy. J Clin Endocrinol Metab 101, 5012-5020. 